\title{
High-Antarctic regular sea urchins - the role of depth and feeding in niche separation
}

Received: 14 October 2002 / Accepted: 19 October 2002 / Published online: 18 December 2002

(C) Springer-Verlag 2002

\begin{abstract}
Regular sea urchins of the families Cidaridae and Echinidae are widespread and sympatrically occurring epibenthic species in Antarctic waters. Food preference and water depth distribution of the five most abundant species (Ctenocidaris gigantea, C. spinosa, Notocidaris mortenseni, Sterechinus antarcticus, S. neumayeri) were analysed based on trawl and photograph samples. Both diet and water depth contribute to niche separation among these species. All sea urchins consume bryozoans and sediment, but echinids feed predominantly on diatoms in the fluff, when available. Cidarids do not consume diatoms, most likely owing to morphological constraints; their typical food consists of sponges and hydroids. C. spinosa and $S$. neumayeri prefer shallow water depths, whereas $N$. mortenseni and $S$. antarcticus prefer deeper regions. C. gigantea is the most variable species regarding food composition and living depth.
\end{abstract}

\section{Introduction}

Members of two regular echinoid families, the Cidaridae and the Echinidae, inhabit the high-Antarctic shelf and slopes of the Weddell Sea. The Echinidae are represented by three species from one family, the abundant Sterechinus neumayeri and S. antarcticus, and the rare $S$. dentifer. Twenty-one species of the Cidaridae have been reported so far, among which Ctenocidaris gigantea, C. spinosa and Notocidaris mortenseni are the most abundant in the Weddell Sea.

$S$. antarcticus and $S$. neumayeri are very similar morphologically and in their life history and population

U. Jacob $(\bowtie) \cdot$ S. Terpstra $\cdot$ T. Brey

Alfred Wegener Institut für Polar- und Meeresforschung,

Ute Jacob, Postfach 120161, 27515 Bremerhaven, Germany

E-mail: ujacob@awi-bremerhaven.de

Tel.: + 49-471-48311327

Fax: + 49-471-48311149 dynamics. They have planktotrophic larvae and can attain individual ages up to 70 years (Bosch et al. 1984; Brey 1991; Brey et al. 1995). The two species prefer different, albeit overlapping, depth ranges. S. neumayeri is restricted to shallow shelf regions, whereas $S$. antarcticus prefers the deeper shelf and slope (Brey and Gutt 1991; David et al. 2000). Little is known about the distribution of Antarctic cidaroids (e.g. David et al. 2000), and even less about their life history and population dynamics, except their obligate brood-protection habit. Nevertheless, they are among the most speciose echinoids in Antarctic waters (Mooi et al. 2000). Regular echinoids are highly mobile. Their unique feeding apparatus, the Aristotle's lantern, permits flexibility regarding size, structure and hardness of food items; consequently, many species are known to be omnivorous (De Ridder and Lawrence 1982). Among the Antarctic species, only the feeding of $S$. neumayeri has been studied in detail (review in McClintock 1994), whereas information on food of cidaroids is quite anecdotical (Fell 1976; De Ridder and Lawrence 1982).

The presence of such a high number of mobile species with potentially similar life habits within the same region raises the question of niche separation. In this study, we investigate whether bathyal distribution and/or feeding preferences play any significant role in niche separation of the five most abundant echinoid species of the Weddell Sea shelf and slope.

\section{Materials and methods}

Study area and sampling

All samples were collected during ten RV "Polarstern" expeditions to the northwestern and southeastern shelf and slope of the Weddell Sea and the adjacent Lazarev Sea between 1983 and 2000. Trawl samples were taken by Agassiz trawl (mouth opening $3 \times 1 \mathrm{~m}$, mesh size $10 \times 10 \mathrm{~mm}$ in the cod end) and a standard 140-ft bottom trawl (see Voss 1988 and Galeron et al. 1992 for further information). Underwater still photographs were taken by a Hasselblad 500 and an electronic flash as described by Gutt (1988). Initially, the two families Cidaridae and Echinidae were not investigated 
simultaneously; therefore, we deal with different albeit overlapping sets of samples for both taxa.

\section{Taxonomy}

Cidaroid sea urchins were identified by the distinct morphology of the oral and aboral primaries according to Phelan (1970), Mortensen (1910) and David et al. (2000). The species of the genus Sterechinus were identified by presence or absence of spiculae, the pattern of the ocular plates, and the globiferous pedicellariae as described by Koehler (1926) and Mortensen (1909, 1920, 1943, 1950).

Abundance, biomass and distribution

Abundance and biomass of sea urchins were inferred from counts on underwater photographs, combined with size-frequency distributions and species composition in trawl samples, as described by Brey and Gutt (1991). Mean biomass was computed by combining station mean abundances, station-specific size frequencies and the body sizemass function established with trawled alcohol-preserved specimens. Bathymetric distribution of single species was inferred from relative contribution to the echinoid fauna of trawl samples. Distribution, abundance and biomass of $S$. antarcticus and $S$. neumayeri were determined by Brey (1991) and Brey and Gutt (1991).

Feeding

For stomach-content analysis, the primary spines of the sea urchins were removed, the corona opened above the fourth ambulacralplate and the stomach removed and opened. The diet of the sea urchins was determined by the pointsmethod, as described by Swynnerton and Worthington (1940) and modified by Dearborn et al. (1986).

Stomach fullness of an individual ( $i$ ) was measured by the stomach fullness index, SFI, according to a qualitative discrete scale ranging from 0 (empty) to 16 (full):

$\mathrm{SFI}_{i} \varepsilon\{0,1,2,4,8,12,16\}$

Stomach contents were identified and grouped into 1 of $m=14$ different food component categories which covered taxonomic groups from Bivalvia to Porifera, eggs, faeces, sediment type I (sand and stones), sediment type II (sponge-spicules and Foraminifera), and unidentifiable organic matter. Volumetric contribution of each food component $(j)$ to total stomach content of individual (i) was determined by the food component value $\mathrm{CPV}_{i, j}$ using the same qualitative scale as above:

$\mathrm{CPV}_{i, j} \varepsilon\{0,1,2,4,8,12,16\}$

The sum of the points assigned to all components $(j)$ in the stomach of 1 individual $(i)$ equals 16 :

$\sum_{j=1}^{m} \mathrm{CPV}_{i, j}=16$

Population diet composition of each species was derived from these data, following the procedures described by Dearborn et al. (1986), Dahm (1996) and Brey (2001). Each food component value $\mathrm{CPV}_{i, j}$ was multiplied by the corresponding stomach fullness index $\mathrm{SFI}_{i}$ to obtain the weighted food component value $\mathrm{WCPV}_{i, j}$

$\mathrm{WCPV}_{i, j}=\left(\mathrm{SFI}_{i} \times \mathrm{CPV}_{i, j}\right) ; \quad 0 \Leftarrow \mathrm{WCPV}_{i, j} \Leftarrow 256$

For standardisation, $\mathrm{WCPV}_{i, j}$ was expressed as a proportion $\mathrm{DC}_{i, j}$ of the sum of points assigned to all food components in all individuals weighted by the number of individuals, $n$
$\mathrm{DC}_{i, j}=\mathrm{WCPV}_{i, j} \times 100 \times n / \sum_{i=1}^{n} \sum_{j=1}^{m} \mathrm{WCPV}_{i, j}$

and average values of $\mathrm{DC}_{i, j}$ and their standard deviation are used to describe and compare average diet composition of the different seaurchin populations:

$\mathrm{DC}_{j}=\sum_{i=1}^{n} \mathrm{DC}_{i, j} / n$

In a second attempt, all $\mathrm{WCPV}_{i, j}$ data were re-arranged in a food component $\times$ specimen matrix and subjected to a similarity analysis by Multi-Dimensional Scaling (MDS, Kruskal and Wish 1978) using the PRIMER software (Field et al. 1982).

\section{Results}

Taxonomy, abundance and biomass

Nine species of Cidaridae and two species of Echinidae (both Sterechinus) were found in the investigated area. Average abundance and biomass of both families are in the same range of slightly above 0.1 ind. $\mathrm{m}^{-2}$ and $1 \mathrm{mg}$ AFDM m ${ }^{-2}$, respectively (Table 1 ).

The five most abundant species in the trawl samples, C. gigantea, C. spinosa, N. mortenseni, S. antarcticus and $S$. neumayeri were selected for further analysis of bathymetric distribution and food preference.

\section{Bathymetric distribution}

The five species are not clearly separated bathymetrically. All are present over a wide depth range across the shelf and slope, although with different centres of distribution. C. spinosa and $S$. neumayeri dominate the shallower regions between 150 and $450 \mathrm{~m}$ whereas C. gigantea, N. mortenseni and S. antarcticus dominate the deeper regions between 450 and $850 \mathrm{~m}$ (Fig. 1). $C$. gigantea has been found down to $>2,000 \mathrm{~m}$ depth in the Weddell Sea (Jacob 2001).

\section{Food preference}

Stomach contents of 220 specimens were analysed: 59 C. gigantea, 66 C. spinosa, 34 N. mortenseni, 31 S. antarcticus and $30 \mathrm{~S}$. neumayeri. All five species taken as a group feed on a wide spectrum of food items. The 14 food component categories reveal similarities as well as differences among the five species (Fig. 2). Bryozoans are a common, as well as a major, food item ( $\leq 100 \%$ of food volume) in all species. Diatoms play a major role in the diet of the echinids $S$. antarcticus $(\leq 72.8 \%$ ) and S. neumayeri ( $\leq 86 \%$ ), but are not consumed at all by the cidarids. In contrast, cidarids feed on Hydrozoa $(\leq 100 \%)$ and Porifera $(\leq 100 \%)$, which play a negliglible role in the nutrition of the echinids. 
Table 1 Cidaridae and Echinidae of the Weddell Sea: sampling method, average abundance and biomass, species indentified, numbers collected and test size range $(\mathrm{mm})$

\begin{tabular}{|c|c|c|}
\hline & Cidaridae & Echinidae \\
\hline
\end{tabular}

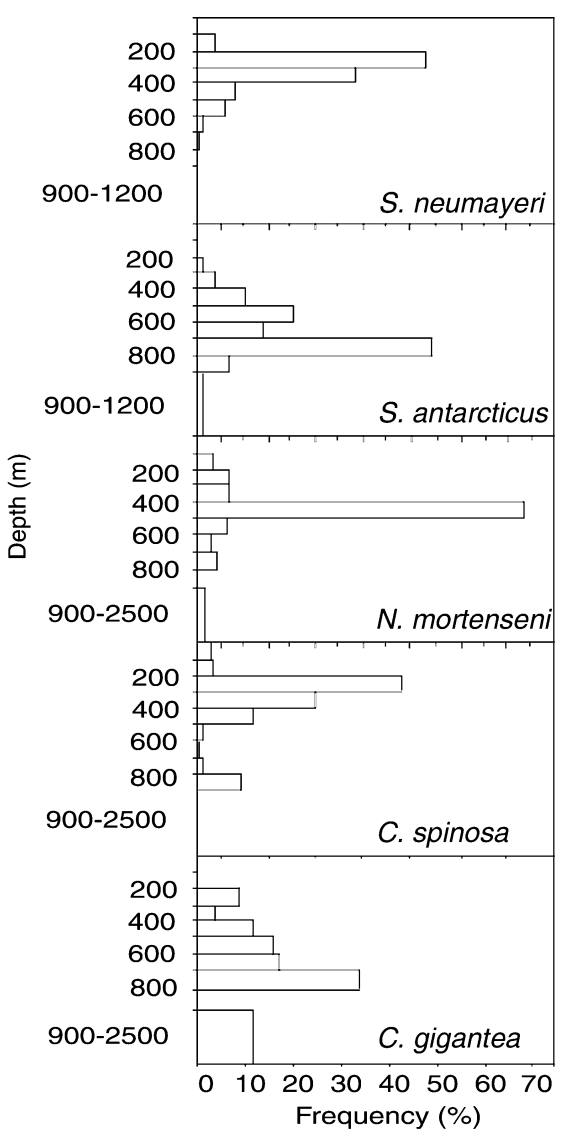

Fig. 1 Bathymetric distribution of the five echinoid species on the Weddell Sea shelf and slope. Bars indicate relative weighed numbers (numbers per depth range were weighted by the corresponding number of trawls)

Multi-dimensional scaling of the 188 specimens with stomach contents, using $\mathrm{WCPV}_{i, j}$ values expressed as $\% \Sigma \mathrm{WCPV}_{i, j}$ of individual (i) and a Bray-Curtis simi- larity matrix reveal some patterns (Fig. 3). The two echinid species occupy a rather exclusive space of the MDS plane, which indicates that individual food composition in these species is: (1) quite similar, (2) less variable among individuals than in the cidarid species, and (3) distinctly different from the food of each cidarid species. Within the Sterechinus "cloud", an upper and a lower cluster can be identified (Fig. 3) which refer to individuals with and without diatoms in their stomach, respectively.

The diet of the three cidarid species is quite similar (Fig. 2) and stomach-content composition is much more variable than in the echinids (Fig. 3).

The small clusters of individuals of mostly the same species visible in the MDS plot (Fig. 3) do not refer to stations, but are formed by specimens having consumed the same main food component.

\section{Discussion}

Methods

Initially the two families Cidaridae and Echinidae were not investigated simultaneously; therefore we deal with different, albeit overlapping, sets of samples for both taxa. Nevertheless, the large number of samples and stations included in our study (Table 1) indicates that both sample sets are representative for the corresponding taxon and are of comparable quality. Evaluation of stomach contents by a qualitative scale is, to some extent, a subjective procedure. This may cause problems when comparing studies carried out by different researchers, but is of less significance within a data set produced by one person (Dearborn et al. 1986; Dahm 1996). As regular sea urchins chew their food, the precise identification of the consumed items is quite laborious and often impossible. The 14 broader components used 


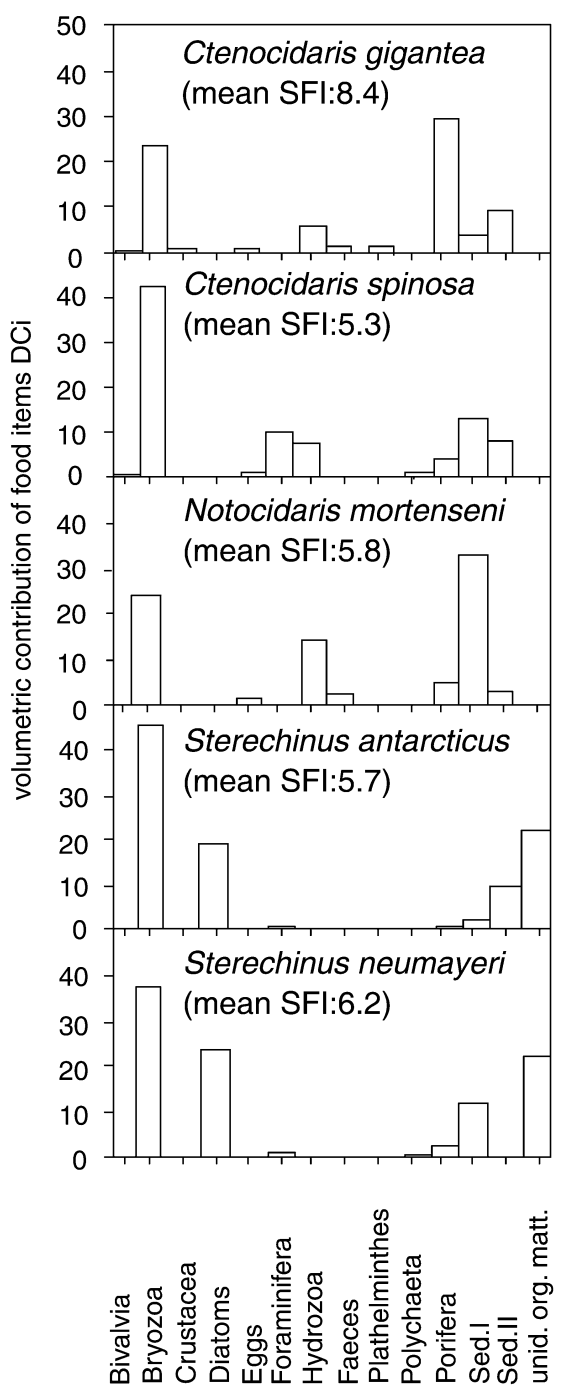

Fig. 2 Average volumetric contribution of 14 food components $\left(\mathrm{DC}_{i}\right)$ to the diet of the species Ctenocidaris gigantea, C. spinosa, Notocidaris mortenseni, Sterechinus antarcticus and $S$. neumayeri (SFI Stomach Fullness Index)

here to categorise echinoid food items (Fig. 2) represent a compromise between resolution and identification effort.

\section{Niche separation}

All five sea urchin species examined here are omnivorous, and cover a wide depth range (Figs. 1,2). Nevertheless, our findings indicate that the two parameters, food and depth, may contribute to species niche separation.

Inter-individual variability of stomach-content composition is high (Fig. 3), but all species feed on bryozoans and sediment as reported in previous studies (Fell 1976; De Ridder and Lawrence 1982). Sponges and Foraminifera are also common food items, whereas bivalves and faeces are less common (Fig. 2).
The one distinct interspecific difference in alimentation are diatoms, which are found in both Sterechinus species, but not in the cidaroids. Obviously Sterechinus collects these diatoms from the sediment surface, where they are deposited during sedimentation events. In Antarctic shelf waters, these events occur during a very short spring/summer period only, and within this time frame spatial and temporal variability are extremely high (Arntz et al. 1990; Bathmann et al. 1991). Nevertheless, the Sterechinus species strongly prefer this food component, as indicated by significant negative correlations between diatoms and other food components in their stomachs (Terpstra 1996) and by the distinction between individuals with and without diatoms in the stomach by the MDS (Fig. 3). Differences in diet composition of $S$. neumayeri and $S$. antarcticus are negligible (Fig. 2) and do not lead to a separation of the two species in the MDS plot (Fig. 3). Depth seems to play the major role in echinid niche separation, because $S$. neumayeri is more abundant above $400 \mathrm{~m}$, and S. antarcticus prefers the deeper regions (Fig. 1 and Brey and Gutt 1991).

Previously cidaroids were assumed to be deposit feeders exclusively (Fell 1976; De Ridder and Lawrence 1982), which is clearly not the case in the three species investigated here. Stomach contents (Fig. 3), especially tissue-bound sponge material, as well as frequent in situ observations on the underwater photographs of cidaroids sitting on sponges, provide strong evidence that cidaroids prey on sponges and other sessile taxa. The extreme variability of stomach content among individuals (Fig. 3) makes it impossible to detect consistent differences in the diet of the three species. However, the largest species, C. gigantea, seems to display a specific combination of features: (1) the highest percentage of sponges in the diet (Fig. 2); (2) the highest inter-individual variability in overall diet composition (Fig. 3); and (3) the highest average stomach-fullness values (Fig. 2). Larger body and lantern size may enable $C$. gigantea to feed on items that are too big, too hard, or otherwise too difficult to be handled by smaller cidarid species. Such an extended availability of ingestible food items would also facilitate the increased depth distribution of this species. The remaining two species, C. spinosa and N. mortenseni, do not show distinct differences in their diet (Fig. 2) and are not clearly separated by the MDS (Fig. 3). However, depth may play a role in niche separation, as the medians of distribution are situated at 200- to 300-m water depth in C. spinosa and 400- to 500-m water depth in N. mortenseni, respectively (Fig. 1, De Ridder et al. 1992; David et al. 2000).

Both diet and depth contribute to niche separation among the five echinoid species compared here. The families Echinidae and Cidaridae are clearly separated by the former's preference for diatoms, which are not consumed at all by the latter. Within the echinids, $S$. neumayeri and $S$. antarcticus are separated by their depth preferences. Within the cidarids, $C$. gigantea shows the least restrictions regarding diet and depth, 


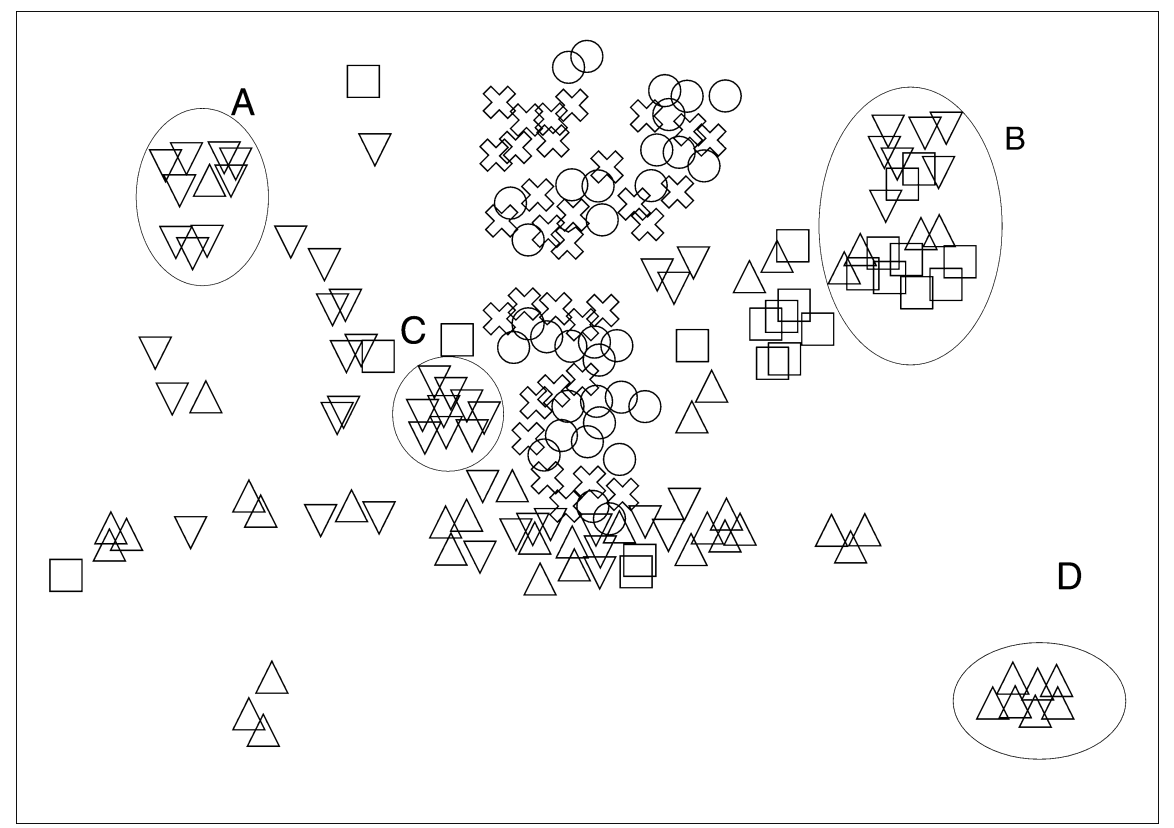

Fig. 3 Multi-dimensional scaling $(M D S$, stress $=0.14)$ of 188 echinoid specimens according to their stomach-content composition as expressed by relative weighted food component values (\%WPCV) ( $\nabla$ Ctenocidaris gigantea, $\Delta$ C. spinosa, $\square$ Notocidaris mortenseni, $\aleph_{3}$ Sterechinus antarcticus, $\bigcirc S$. neumayeri; A cluster of $C$. gigantea mainly feeding on sponges; $B$ cluster of cidarids mainly feeding on sediments; $C$ cluster of $C$. gigantea mainly feeding on Bryozoa; $D$ cluster of $C$. spinosa mainly feeding on Bryozoa and Foraminifera)

most likely because of its greater size. The remaining species, C. spinosa and $N$. mortenseni, are separated by their depth preferences, with the latter inhabiting somewhat greater depths.

It is difficult to decide whether the Cidaridae or the Echinidae are ecologically more successful in our investigation area. Nine cidarid species are present compared to only two echinid species, but abundance and biomass of both families are in the same range, 0.1 ind. $\mathrm{m}^{-2}$ and $1 \mathrm{mg}$ AFDM m${ }^{-2}$. Hence, regarding reproductive strategies, this comparison does not indicate an advantage of brood protection over free-swimming pelagic larvae in polar environments (see discussion in Pearse et al. 1991 and Arntz et al. 1994).

Acknowledgements We are grateful to Rich Mooi, John Pearse and an anonymous referee for their extensive and helpful comments on the manuscript.

\section{References}

Arntz WE, Brey T, Gerdes D, Gorny M, Gutt J, Hain S, Klages M (1990) Patterns of life history and population dynamics of benthic invertebrates under high Antarctic conditions of the Weddell Sea. In: Colombo G, Ferrary I, Ceccherelli VU, Rossi $\mathrm{R}$ (eds) Marine eutrophication and population dynamics. Olsen and Olsen, Fredensborg, pp 221-230

Arntz WE, Brey T, Gallardo VA (1994) Antarctic zoobenthos. Oceanogr Mar Biol Annu Rev 32:241-304
Bathmann U, Fischer G, Müller PJ, Gerdes D (1991) Short- term variations in particulate matter sedimentation off Kapp Norvegia, Weddell Sea, Antarctica: relation to water mass advection, ice cover, plankton biomass and feeding activity. Polar Biol 11:185-195

Bosch I, Beauchamp KA, Steele ME, Pearse J (1984) Slow developing feeding larvae of a common Antarctic sea urchin reared through metamorphosis. Am Zool 24:681

Brey T (1991) Population dynamics of Sterechinus antarcticus (Echinodermata: Echinoidea) on the Weddell Sea shelf and slope, Antarctica. Antarct Sci 3:251-256

Brey T (2001) Population dynamics in benthic invertebrates. A virtual handbook Version $01.2 \mathrm{http}: / /$ www.awi-bremerhaven.de/Benthic/Ecosystem/FoodWeb/Handbook/main.html. Alfred Wegener Institute for Polar Marine Research

Brey T, Gutt J (1991) The genus Sterechinus (Echinodermata: Echinoidea) on the Weddell Shelf and slope (Antarctica):distribution, abundance and biomass. Polar Biol 11: 227-232

Brey T, Pearse J, Basch L, McClintock J, Slattery M (1995) Growth and production of Sterechinus neumayeri (Echinoidea: Echinodermata) in McMurdo Sound, Antarctica. Mar Biol 124:279292

Dahm C (1996) Ökologie und Populationsdynamik antarktischer Ophiuroiden (Echinodermata). Ber Polarforsch 194:1-289

David B, Chone T, De Ridder C, Festeau A (2000) Antarctic echinoids. An interactive database on CD-ROM version 1.0 Biogeosciences, University of Burgundy

Dearborn JH, Ferrari FD, Kelly CE (1986) Can pelagic aggregations cause benthic satiations? Feeding biology of the Antarctic brittle star Astrotoma agassizii (Echinodermata: Ophiuroidea). Antarct Res Ser 44:1-28

De Ridder C, Lawrence JM (1982) Food and feeding mechanisms: Echinoidea. In: Jangoux M, Lawrence JM (eds) Echinoderm nutrition. Balkema, Rotterdam, pp 57-115

De Ridder C, David B, Larrain A (1992) Antarctic and Subantarctic echinoids from "Marion Dufresne" expeditions MD03, MD04, MD08 and from the Polarstern expedition Epos III. Bull Mus Natl Hist Nat Paris Ser 4 14A:405-441

Fell FJ (1976) The cidaroida (Echinodermata: Echinoidea) of Antarctica and the Southern Oceans. PhD Thesis, University of Maine, Orono

Field JG, Clarke KR, Warwick RM (1982) A practical strategy for analysing multispecies distribution patterns. Mar Ecol Prog Ser $8: 37-52$ 
Galeron J, Herman RL, Arnaud PM, Arntz WE, Hain S, Klages M (1992) Macrofaunal communities on the continental shelf and slope of the southeastern Weddell Sea, Antarctica. Polar Biol $12: 283-290$

Gutt J (1988) Zur Verbreitung und Ökologie der Seegurken (Holothuroidea: Echinodermata) im Weddellmeer (Antarktis). Rep Polar Res 41:87

Jacob U (2001) Ökologie der cidaroiden Seeigel des Weddellmeeres. Thesis, Bremen University

Koehler R (1926) Echinodermata: Echinoidea. In: Harrison L (ed) Australian Antarctic expedition 1911-1914. Scientific Rep VIII. Kent, Sydney, pp 29-38

McClintock JB (1994) Trophic biology of Antarctic shallow water echinoderms. Mar Ecol Prog Ser 111:191-202

Mooi R, David B, Fell FJ, Chone T (2000) Three new species of bathyal cidaroids (Echinoidea: Echinodermata) from the Antarctic region. Proc Biol Soc Wash 113:224-237

Mortensen T (1909) Die Echinoiden der deutschen Südpolar- Expedition 1901-1903. In: Drygalski E (ed) Deutsche SüdpolarExpedition 1901-1903, vol XI, Zool III. Reimer, Berlin

Mortensen T (1910) The Echinoidea of the Swedish South Polar Expedition. Schwedische Südpolar Exped 1901-1903 6 Zool $2: 1-114$
Mortensen T (1920) The Echinoidea of the Swedish South Polar expedition. In: Nordensköld O (ed) Wissenschaftliche Ergebnisse der Schwedischen Südpolar-Expedition 1901-1903, vol VI. Asher, Berlin

Mortensen T (1943) A monograph of the echinoidea, vol III, 3. Reitzel, Copenhagen

Mortensen T (1950) Echinoidea. BANZ Antarctic Research Expedition 1929-1931. Rep Ser B vol IV

Pearse J, McClintock J, Bosch I (1991) Reproduction of Antarctic benthic marine invertebrates: tempos, modes and timing. Am Zool 31:65-80

Phelan T (1970) A field guide to the cidaroid echinoids of the Northwestern Atlantic Ocean, Gulf of Mexico and the Caribbean Sea. Smithsonian Contrib Zool 40 III. Smithsonian Institution Press, Washington DC

Swynnerton GH, Worthington EB (1940) Note on food of fish in Havaswater (Westmorland). J Anim Ecol 9:183-187

Terpstra S (1996) Die Nahrung dominanter Echinoiden (Echinodermata) des antarktischen Weddellmeeres. Thesis, Hamburg University

Voss J (1988) Zoogeography and community analysis of macrozoobenthos of the Weddell Sea (Antarctica). Ber Polarforsch 45:145 